\title{
Effects of L-arginine and L-nitro-arginine methyl ester on recovery of neonatal lamb hearts after cold ischemia
}

\author{
Evidence for an important role of endothelial production of \\ nitric oxide
}

Myocardial ischemia and reperfusion results in both ventricular and endothelial dysfunction. We have found that the endothelial defect is a reduced vasodilator response to an intraarterial infusion of acetylcholine that is likely due to reduced nitric oxide release, and we have hypothesized that reduced endothelial nitric oxide production contributes to postischemic cardiac dysfunction. However, others report that nitric oxide is deleterious after ischemia. We therefore examined the effects of infusions of $\mathrm{L}$-arginine $(3 \mathrm{mmol} / \mathrm{L})$, a precursor of nitric oxide, $D$-arginine $(3 \mathrm{mmol} / \mathrm{L})$, an inactive stereoisomer of $\mathrm{L}$-arginine, $\mathrm{L}$-nitro-arginine methyl ester $(1 \mathrm{mmol} / \mathrm{L})$; a competitive inhibitor of nitric oxide synthase, and L-nitro-arginine methyl ester $(1 \mathrm{mmol} / \mathrm{L})$ plus $\mathrm{L}$-arginine $(3 \mathrm{mmol} / \mathrm{L})$ versus controls in isolated blood-perfused neonatal lamb hearts having 2 hours of cold cardioplegic ischemia. L-nitro-arginine methyl ester was given before reperfusion, and L-arginine and D-arginine were infused for the first 20 minutes of postischemic reperfusion. At 30 minutes of reperfusion, by comparison with the control group, the L-arginine group showed significantly better recovery $(p<$ 0.05) of left ventricular systolic function (maximum developed pressure, developed pressure at V10 [balloon volume to produce an end-diastolic pressure of $10 \mathrm{~mm} \mathrm{Hg}$ during baseline measurement], positive maximum dP/dt, and $\mathrm{dP} / \mathrm{dt}$ at $\mathrm{V10}$ ), diastolic function (negative maximum $\mathrm{dP} / \mathrm{dt}$ ), coronary blood flow, and endothelial function assessed by the coronary vascular resistance response to acetylcholine. The L-nitro-arginine methyl ester hearts showed a significantly poorer recovery $(p<$ 0.05) in left ventricular function, coronary blood flow, and endothelial function than the control group. These effects of L-nitro-arginine methyl ester were reversed to equal control values by adding a $3 \mathrm{mmol} / \mathrm{L}$ concentration of $L$-arginine to $L$-nitro-arginine methyl ester. There were no significant differences in the recovery of any variables between the D-arginine and control groups. These results point to an important salutary role for the endothelial production of nitric oxide in cardiac recovery after hypothermic ischemia in neonatal lamb hearts. The mechanism of these beneficial effects of L-arginine after ischemia and reperfusion is likely due to enhancement of the endothelial production of nitric oxide. (J THORAC CARDIOVASC SURG 1995;109:81-7)

Takeshi Hiramatsu, MD (by invitation), Joseph M. Forbess, MD (by invitation), Takuya Miura, MD (by invitation), and John E. Mayer, Jr., MD, Boston, Mass.

From the Department of Cardiac Surgery, Harvard Medical School and the Children's Hospital, Boston, Mass.

Read at the Seventy-fourth Annual Meeting of The American Association for Thoracic Surgery, New York, N.Y., April 24-27, 1994.

Address for reprints: John E. Mayer Jr., MD, Department of Cardiac Surgery, Children's Hospital, 300 Longwood Ave., Boston, MA 02115.
$P$ Pror experiments from our laboratory on hypothermic ischemia and reperfusion in neonatal lamb hearts have shown that (1) myocardial ischemia and reperfusion results in both ventricular and endothe-

Copyright (C) 1995 by Mosby-Year Book, Inc. $0022-5223 / 95 \$ 3.00+0 \quad \mathbf{1 2 / 6 / 6 0 2 4 5}$ 
lial dysfunction ${ }^{1}$ and (2) the endothelial dysfunction is characterized by reduced release of nitric oxide after hypothermic ischemia and reperfusion. ${ }^{2} \mathrm{Re}-$ cent investigations have characterized endotheliumderived relaxing factor as nitric oxide, ${ }^{3,4}$ which is produced from the semiessential amino acid Larginine as it is converted to L-citrulline by nitric oxide synthase in endothelial cells. ${ }^{5,6}$ In the vascular system, nitric oxide release from endothelial cells causes vasorelaxation ${ }^{7,8}$ but also inhibits platelet ${ }^{9}$ and leukocyte aggregation. ${ }^{10}$ Moreover, nitric oxide is a primary radical species and is inactivated by superoxide radicals ${ }^{11,12}$; conversely, nitric oxide may neutralize superoxide radicals. ${ }^{13}$ Despite these potential benefits, nitric oxide production has been shown to be deleterious by some authors, ${ }^{14}$ but others report that nitric oxide may be beneficial after northothermic ischemia and reperfusion. ${ }^{15-19}$ This study was designed to examine the role of endothelial production of nitric oxide after hypothermic ischemia and reperfusion with L-arginine, a nitric oxide precursor, and L-nitro-arginine methyl ester (L-NAME), a competitive inhibitor of nitric oxide synthase, in neonatal hearts.

\section{Materials and methods}

Experimental preparation. An isolated blood-perfused heart model, previously described, ${ }^{1,2}$ was used to study 40 hearts from neonatal lambs ( 2.3 to $5.9 \mathrm{~kg}, 2$ to 7 days old). Coronary perfusion was established with a roller pump and oxygenator system before isolation of the heart. Heparinized fresh homologous blood was used as the perfusate. Arterial pH was kept at 7.4 (corrected to perfusate temperature). Myocardial temperature was monitored by thermal probes and the perfusate was controlled at $37^{\circ} \mathrm{C}$ except during the hypothermic phase. Coronary perfusion pressure was maintained at $60 \mathrm{~mm} \mathrm{Hg}$ except during the hypothermic and reperfusion phases. A latex balloon that contained a pressure transducer was placed inside the left ventricle through the apex to measure left ventricular function.

Measurements. Left ventricular function was measured during isovolumic contraction by inflating the intraventricular balloon as described previously. ${ }^{1,2}$ The recovery of systolic function was evaluated by measuring the maximum developed pressure, positive maximum rate of left ventricular pressure rise $(\mathrm{dP} / \mathrm{dt})$, peak developed pressure at a constant balloon volume (V10), and peak $\mathrm{dP} / \mathrm{dt}$ at V10. V10 was defined as the balloon volume to produce an end-diastolic pressure of $10 \mathrm{~mm} \mathrm{Hg}$ during baseline measurement. To assess the diastolic function, we measured negative maximum $\mathrm{dP} / \mathrm{dt}$ and end-diastolic pressure at V10. Coronary blood flow (CBF) was assessed by an electromagnetic flowmeter, which was connected to the venous cannula. Coronary endothelial function was assessed by the coronary vascular resistance (CVR) response to acetylcholine $\left(10^{-7} \mathrm{~mol} / \mathrm{L}\right)$ infusion. ${ }^{1,2}$ Maxi- mum decrease in CVR during the acetylcholine infusion, divided by baseline CVR, was defined as the CVR response. To assess endothelium-independent vasodilator capacity, we infused trinitroglycerin $\left(3 \times 10^{-5} \mathrm{~mol} / \mathrm{L}\right)$ in the same way and measured the CVR response. Arterial and venous blood was collected and myocardial oxygen consumption was calculated from the hemoglobin concentration, the oxygen content, and saturation..$^{1,2}$

Experimental protocol. Baseline measurements were made after a 20 -minute equilibrium period. Then the perfusate was cooled to $15^{\circ} \mathrm{C}$. After 10 minutes of cooling (myocardial temperature $=15^{\circ} \mathrm{C}$ ), coronary perfusion was stopped and a $20 \mathrm{ml} / \mathrm{kg}$ dose of cardioplegic solution was given, followed by topical cooling (myocardial temperature was kept at $10^{\circ} \mathrm{C}$ ). A second dose of $10 \mathrm{ml} / \mathrm{kg}$ was given after 60 minutes. The cardioplegic solution was $2.5 \%$ dextrose solution with potassium chloride in a concentration of $20 \mathrm{mEq} / \mathrm{L}$. Reperfusion was begun with the perfusate at room temperature and then rewarmed to normothermia over 25 minutes. Mean coronary perfusion pressure was maintained at $20 \mathrm{~mm} \mathrm{Hg}$ for the first 5 minutes, raised to $40 \mathrm{~mm} \mathrm{Hg}$ for the second 5 minutes, and then kept at $60 \mathrm{~mm} \mathrm{Hg}$ until the end of the experiment. ${ }^{1,2} \mathrm{~A}$ high oxygen concentration was used during the first 15 minutes of reperfusion. Thereafter the gas was changed to a low oxygen concentration.

Experimental groups. The hearts were divided into five groups: (1) In the L-arginine group $(n=8)$, the nitric oxide precursor $\mathrm{L}$-arginine was infused into the arterial cannula during the first 20 minutes of reperfusion at a rate calculated to achieve a concentration of $3 \mathrm{mmol} / \mathrm{L}$ in the coronary blood. (2) In the D-arginine group $(n=8)$, $\mathrm{D}$-arginine, an inactive stereoisomer of $\mathrm{L}$-arginine, was infused at a concentration of $3 \mathrm{mmol} / \mathrm{L}$ in the same manner as group L-arginine. (3) In the L-NAME group $(n=8)$, a $1 \mathrm{mmol} / \mathrm{L}$ dose of L-NAME, a competitive inhibitor of nitric oxide synthase, was given in the oxygenator to achieve a concentration of $1 \mathrm{mmol} / \mathrm{L}$ before reperfusion. (4) In the L-arginine + L-NAME group $(n=$ 8 ), L-arginine and L-NAME were given in the same way as in the L-arginine and L-NAME groups. (5) In the control group $(n=8)$, blood alone was reperfused without intervention. In two other no-ischemia groups, continuous normothermic perfusion was carried out. A $3 \mathrm{mmol} / \mathrm{L}$ dose of L-arginine was infused in one group (20 minutes) and continuous perfusion without L-arginine was conducted in the second $(n=8$ each). Animals in this study received humane care in compliance with the "Principles of Laboratory Animal Care" formulated by the National Society for Medical Research and the "Guide for the Care and Use of Laboratory Animals" prepared by the National Academy of Sciences and published by the National Institutes of Health (NIH Publication No. 86-23, revised in 1985).

Statistics. All values are expressed as mean \pm standard deviation and are analyzed by a statistical analysis system. One-way analysis of variance and repeated-measures twoway analysis of variance were used to compare the differences in recovery between groups. Data were compared by the Student-Newman-Keuls test if analysis of variance indicated significant differences. A $p$ value less than 0.05 was considered to be significant. 
Table I. Baseline values and percent recovery of ventricular function

\begin{tabular}{|c|c|c|c|c|c|}
\hline & \multicolumn{5}{|c|}{ Group } \\
\hline & Control & $L-A R G$ & $D-A R G$ & $L-N A M E$ & $A R G+N A M E$ \\
\hline Heart rate (beats/min) & $198 \pm 19$ & $212 \pm 19$ & $213 \pm 17$ & $217 \pm 14$ & $220 \pm 11$ \\
\hline \multicolumn{6}{|l|}{$\mathrm{DP}(\max )$} \\
\hline Baseline $(\mathrm{mm} \mathrm{Hg})$ & $125 \pm 14$ & $133 \pm 11$ & $131 \pm 16$ & $135 \pm 19$ & $143 \pm 9$ \\
\hline Percent recovery & $75.5 \pm 8.0$ & $94.5 \pm 3.4^{*}$ & $79.4 \pm 4.7$ & $66.4 \pm 4.7^{*}$ & $79.6 \pm 3.6$ \\
\hline \multicolumn{6}{|l|}{$\mathrm{DP}(\mathrm{V} 10)$} \\
\hline Baseline (mm Hg) & $118 \pm 17$ & $129 \pm 11$ & $121 \pm 16$ & $124 \pm 19$ & $130 \pm 12$ \\
\hline Percent recovery & $75.1 \pm 8.0$ & $90.3 \pm 5.3^{*}$ & $80.8 \pm 4.1$ & $66.1 \pm 10.1^{*}$ & $80.4 \pm 5.5$ \\
\hline \multicolumn{6}{|l|}{$\mathrm{dP} / \mathrm{dt}(\max )$} \\
\hline Baseline $(\mathrm{mm} \mathrm{Hg} / \mathrm{sec})$ & $1910 \pm 311$ & $2034 \pm 208$ & $1927 \pm 415$ & $2079 \pm 399$ & $2160 \pm 234$ \\
\hline Percent recovery & $68.3 \pm 8.8$ & $88.8 \pm 3.8^{*}$ & $70.8 \pm 7.5$ & $54.9 \pm 10.5^{*}$ & $69.4 \pm 3.8$ \\
\hline \multicolumn{6}{|l|}{$\mathrm{dP} / \mathrm{dt}(\mathrm{V} 10)$} \\
\hline Baseline $(\mathrm{mm} \mathrm{Hg} / \mathrm{sec})$ & $1765 \pm 352$ & $1910 \pm 249$ & $1740 \pm 415$ & $1890 \pm 315$ & $1944 \pm 342$ \\
\hline $\begin{array}{l}\text { Percent recovery } \\
-\mathrm{dP} / \mathrm{dt}(\max )\end{array}$ & $66.8 \pm 11.2$ & $87.5 \pm 4.9^{*}$ & $73.1 \pm 7.4$ & $55.5 \pm 10.7^{*}$ & $71.1 \pm 7.9$ \\
\hline Baseline $(\mathrm{mm} \mathrm{Hg} / \mathrm{sec})$ & $1325 \pm 125$ & $1432 \pm 145$ & $1370 \pm 228$ & $1480 \pm 280$ & $1530 \pm 170$ \\
\hline Percent recovery & $60.7 \pm 6.8$ & $74.1 \pm 9.5^{*}$ & $62.6 \pm 9.3$ & $46.4 \pm 11.1^{*}$ & $59.6 \pm 6.0$ \\
\hline \multicolumn{6}{|l|}{ EDP (V10) } \\
\hline Percent baseline & $92.5 \pm 17.1$ & $76.3 \pm 21.2 \dagger$ & $113.8 \pm 46.4$ & $126.9 \pm 52.6$ & $90.0 \pm 21.2$ \\
\hline
\end{tabular}

$D P$ (max), Maximum peak developed pressure; $D P(V 10)$, peak developed pressure at a constant balloon volume (V10); $d P / d t$ (max), maximum of peak positive $\mathrm{LV} \mathrm{dP/dt;} d P / d t(V 10)$, $\mathrm{LV} \mathrm{dP/dt} \mathrm{at} \mathrm{V10;} \mathrm{V10,} \mathrm{volume} \mathrm{to} \mathrm{produce} \mathrm{an} \mathrm{end-diastolic} \mathrm{pressure} \mathrm{of} 10 \mathrm{~mm} \mathrm{Hg}$ during preischemic period; $-d P / d t$ (max), maximum of peak negative LV dP/dt; $E D P(V 10)$, end-diastolic pressure at $\mathrm{V} 10 ; L-A R G$, L-arginine; $D-A R G$, D-arginine; $L-N A M E$, L-nitro-arginine methyl ester. Data are mean \pm standard deviation.

${ }^{*} p<0.05$ versus control.

$\dagger p<0.05$ versus L-NAME group.

Table II. Baseline values and percent recovery of coronary blood flow

\begin{tabular}{|c|c|c|c|c|c|}
\hline & \multicolumn{5}{|c|}{ Group } \\
\hline & Control & $L-A R G$ & $D-A R G$ & $L-N A M E$ & $A R G+N A M E$ \\
\hline Baseline (ml/100 gm) & $261 \pm 43$ & $248 \pm 34$ & $311 \pm 55$ & $309 \pm 44$ & $275 \pm 109$ \\
\hline \multicolumn{6}{|l|}{ Percent baseline } \\
\hline At 5 min reperfusion & $21.3 \pm 14.8$ & $38.4 \pm 32.8$ & $22.2 \pm 5.9$ & $9.2 \pm 6.2$ & $19.6 \pm 10.1$ \\
\hline At 10 min reperfusion & $67.4 \pm 28.3$ & $110.1 \pm 48.4^{*}$ & $61.8 \pm 13.1$ & $38.3 \pm 11.9$ & $49.7 \pm 17.3$ \\
\hline At 15 min reperfusion & $113.6 \pm 29.2$ & $201.2 \pm 28.0^{*}$ & $129.9 \pm 18.8$ & $83.4 \pm 14.5^{*}$ & $123.0 \pm 22.4$ \\
\hline At 20 min reperfusion & $119.4 \pm 34.4$ & $212.2 \pm 38.4^{*}$ & $143.8 \pm 18.2$ & $77.3 \pm 18.4^{*}$ & $118.0 \div 12.7$ \\
\hline At 25 min reperfusion & $122.2 \pm 34.5$ & $209.4 \pm 42.2^{*}$ & $139.0 \pm 15.5$ & $84.6 \pm 24.9^{*}$ & $111.3 \pm 12.6$ \\
\hline At 30 min reperfusion & $133.0 \pm 31.6$ & $203.2 \pm 32.1^{*}$ & $140.0 \pm 16.8$ & $86.0 \pm 22.6^{*}$ & $120.7 \pm 19.9$ \\
\hline
\end{tabular}

Data are mean \pm standard deviation. $L-A R G$, L-arginine; $D-A R G$, D-arginine; $L-N A M E$, L-nitro-arginine methyl ester.

${ }^{*} p<0.05$ versus control group.

\section{Results}

Baseline measurements (Tables I to IV). There was no significant difference in baseline data among the five groups.

Left ventricular function (Table I). Compared with the control group, L-Arginine-treated hearts had significantly greater recovery of all left ventricular systolic function indices (including maximum developed pressure, positive maximum $\mathrm{dP} / \mathrm{dt}$, developed pressure at $\mathrm{V} 10$, and $\mathrm{dP} / \mathrm{dt}$ at $\mathrm{V} 10$ ) and negative maximum $\mathrm{dP} / \mathrm{dt}$ at 30 minutes of reperfusion $(p<0.05)$. Conversely, L-NAME-treated hearts showed significantly reduced recovery of all systolic function indices and negative maximum $\mathrm{dP} / \mathrm{dt}$ compared with the control group $(p<0.05)$. The L-arginine hearts showed significantly better recovery of end-diastolic pressure at V10 than the L-NAME hearts $(p<0.05)$. The recovery in the D-arginine and L-arginine + L-NAME groups was not significantly different from that in the control group.

CBF (Table II). The L-arginine group had significantly higher CBF than the control group from 10 minutes of reperfusion $(p<0.05)$. The L-NAME group had significantly lower CBF than the control group from 15 minutes of reperfusion $(p<0.05)$. The recovery in the $\mathrm{D}$-arginine and L-argininet 
Table III. Baseline values and percent baseline of myocardial oxygen consumption

\begin{tabular}{lccccc}
\hline & \multicolumn{4}{c}{ Group } \\
\cline { 2 - 5 } & Control & L-ARG & D-ARG & L-NAME & ARG $+N A M E$ \\
\hline Baseline $\left(10^{-4} \mathrm{ml} / \mathrm{gm}\right)$ & $3.31 \pm 0.70$ & $4.16 \pm 0.64$ & $4.18 \pm 1.13$ & $4.41 \pm 1.37$ & $4.55 \pm 1.00$ \\
Percent baseline & & & & & \\
At 5 min reperfusion & $44.5 \pm 29.4$ & $46.6 \pm 24.7$ & $48.9 \pm 22.2$ & $18.6 \pm 4.1$ & $45.0 \pm 33.3$ \\
At 15 min reperfusion & $85.0 \pm 26.5$ & $104.2 \pm 30.3^{*}$ & $84.8 \pm 28.3$ & $62.3 \pm 17.0$ & $96.1 \pm 9.1$ \\
At 20 min reperfusion & $87.6 \pm 15.3$ & $111.8 \pm 27.1^{*}$ & $74.5 \pm 20.3$ & $51.7 \pm 5.0^{*}$ & $69.1 \pm 20.7$ \\
At 30 min reperfusion & $76.1 \pm 22.1$ & $96.8 \pm 17.6 \dagger$ & $78.1 \pm 22.0$ & $63.0 \pm 8.8$ & $74.4 \pm 13.3$ \\
\hline
\end{tabular}

Data are mean \pm standard deviation. $L-A R G$, L-arginine; $D-A R G$, D-arginine; $L-N A M E$, L-nitro-arginine methyl ester.

${ }^{*} p<0.05$ versus control group.

$\uparrow p<0.05$ versus $\mathbf{l}$-NAME group.

Table IV. Baseline values and percent recovery of coronary endothelial function

\begin{tabular}{lllllc}
\hline & \multicolumn{5}{c}{ Group } \\
\cline { 2 - 6 } & \multicolumn{1}{c}{ Control } & \multicolumn{1}{c}{$L-A R G$} & D-ARG & L-NAME & ARG+NAME \\
\hline Baseline CVRR by ACh (\%) & $13.5 \pm 5.9$ & $14.1 \pm 5.6$ & $14.2 \pm 3.5$ & $13.1 \pm 3.0$ & $13.6 \pm 5.1$ \\
Percent recovery of CVRR to ACh & $39.2 \pm 13.9$ & $61.0 \pm 14.8^{*}$ & $40.1 \pm 10.8$ & $14.1 \pm 5.3^{*}$ & $29.0 \pm 8.8$ \\
Baseline CVRR by TNG (\%) & $14.9 \pm 2.4$ & $15.0 \pm 4.7$ & $15.7 \pm 3.1$ & $14.9 \pm 2.8$ & $14.1 \pm 3.0$ \\
Percent recovery of CVRR to TNG & $42.4 \pm 15.6$ & $36.4 \pm 15.4$ & $38.2 \pm 7.3$ & $50.7 \pm 14.3$ & $42.1 \pm 22.4$
\end{tabular}

Data are mean \pm standard deviation. $C V R R$, Coronary vascular resistance response; $A C h$, acetylcholine; $T N G$, trinitroglycerin; $L-A R G, L-a r g i n i n e ; D-A R G$, D-arginine; $L-N A M E$, L-nitro-arginine methyl ester.

${ }^{*} p<0.05$ versus control group.

L-NAME groups was not significantly different from that in the control group. There was no significant intergroup difference in heart rate at any time (data not shown).

Myocardial oxygen consumption (Table III). At 15 and 20 minutes of reperfusion, the L-arginine hearts had significantly higher myocardial oxygen consumption than the control group $(p<0.05)$. The L-NAME group demonstrated significantly reduced myocardial oxygen consumption compared with the control group at 20 minutes of reperfusion $(p<$ $0.05)$ and compared with the L-arginine group at 30 minutes of reperfusion $(p<0.05)$. The values in the $D$-arginine and L-arginine $+\mathrm{L}-\mathrm{NAME}$ groups were not significantly different from that in the control group.

Coronary endothelial function (CVR response) (Table IV). Recovery of CVR response to acetylcholine at 30 minutes of reperfusion was significantly better in the L-arginine group than in the control group $(p<0.05)$. The L-NAME group showed significantly reduced CVR response to acetylcholine compared with the control group $(p<$ $0.05)$. However, all five groups had the same degree of recovery of CVR response to trinitroglycerin infusion at 30 minutes of reperfusion.
Effects of L-arginine at normothermia without ischemia. To assess the effect of L-arginine at normothermia without ischemia, we infused a $3 \mathrm{mmol} / \mathrm{L}$ dose of L-arginine for 20 minutes in the same isolated heart model and examined the change of CBF, left ventricular function, and CVR response to acetylcholine 10 minutes later. The percent baseline of CBF was $121.3 \% \pm 13.6 \%$ in $\mathrm{L}$-arginine hearts and $112.2 \% \pm 14.1 \%$ in control hearts, and there was no significant difference between the two groups. As for left ventricular function, the percent of baseline for maximum developed pressure and positive $\mathrm{dP} / \mathrm{dt}$ was $96.8 \% \pm 4.8 \%$ and $96.7 \% \pm$ $5.7 \%$, respectively, in the L-arginine group and $92.5 \% \pm 3.3 \%$ and $92.8 \% \pm 3.5 \%$, respectively, in the control group. There were no significant differences between the two groups in the left ventricular functional indices. The percent baseline of CVR response to acetylcholine was $73.1 \% \pm 24 \%$ in the L-arginine group and $70.5 \% \pm 18.3 \%$ in the control group, and there was no significant intergroup difference.

\section{Discussion}

The present study demonstrates that infusion of L-arginine, but not D-arginine, during early reperfu- 
sion improved the recovery of systolic and diastolic left ventricular function, CBF, myocardial oxygen consumption, and endothelial function of neonatal lamb hearts after 2 hours of hypothermic cardioplegic ischemia. L-NAME reduced recovery of left ventricular function, $\mathrm{CBF}$, and endothelial function, and these effects of L-NAME were reversed to equal control values by adding L-arginine to L-NAME. These results strongly suggest that administration of L-arginine during reperfusion may be a useful therapeutic maneuver.

The exact mechanism by which L-arginine has a beneficial effect remains speculative, but it seems quite likely to involve nitric oxide production. One possible mechanism would be through increased coronary blood flow, ${ }^{7,8}$ assuming that endothelial nitric oxide release is increased by supplying more substrate for nitric oxide production (L-arginine) during reperfusion. The significantly higher levels of $\mathrm{CBF}$ after ischemia in the L-arginine group and the significantly reduced postischemic CBF in the LNAME group would support this hypothesis. Our laboratory has previously found that administration of trinitroglycerin (which likely works through a nitric oxide mechanism) would offset the deleterious effects of high-pressure reperfusion. ${ }^{20} \mathrm{We}$ also have found that trinitroglycerin provided a better recovery of mechanical function in the postischemic period after cold cardioplegic ischemia. ${ }^{21}$ Increases in CBF may potentially lead to improved ventricular function through the Gregg or "garden hose" effect. ${ }^{22}$ However, recent experiments from our laboratory have shown that postischemic infusion of theophylline (an adenosine receptor antagonist) caused increased CBF and lowered CVR but was associated with worse recovery of ventricular function. $^{23}$ Therefore, coronary vasodilation during reperfusion is not always associated with improved recovery of contractile function after hypothermic ischemia. Moreover, the results of the infusion of a $3 \mathrm{mmol} / \mathrm{L}$ concentration of $\mathrm{L}$-arginine at normothermia suggest that in our isolated heart model, Larginine itself does not induce significant coronary vasodilation at normothermia without ischemia. It is clearly possible that the beneficial vasodilatory effect of L-arginine is particularly important only after ischemia and reperfusion.

A number of recent studies are pertinent to the current study and support its conclusions. Normothermic ischemia and reperfusion have been shown to result in diminished nitric oxide release from endothelial cells, ${ }^{24}$ and attempts have been made to supplement the reduced nitric oxide to attenuate myocardial injury associated with ischemia and reperfusion injury. There have been reports that the administration of a nitric oxide donor, ${ }^{15}$ nitric oxide itself, ${ }^{16}$ or L-arginine will ameliorate reperfusion injury after normothermic ischemia in cats ${ }^{17}$ and dogs. ${ }^{18}$ A recent study in patients with coronary artery disease showed that $\mathrm{L}$-arginine improved exercise-induced myocardial perfusion abnormalities. $^{19}$ In contrast, Takeuchi and associates ${ }^{14}$ reported a negative inotropic effect of L-arginine in isolated crystalloid-perfused rabbit hearts. This discrepancy may be due to the difference between blood and crystalloid perfusion, although there was no ischemia in the Takeuchi experiments. Crystalloid perfusion may induce maximum vasodilation from the baseline measurement.

If nitric oxide release is maintained close to the site of injury, it could have cytoprotective effects by inhibiting neutrophil aggregation and adherence. Recently, nitric oxide has been shown to be an endogenous inhibitor of leukocyte chemotaxis, ${ }^{25}$ adherence, ${ }^{26}$ and activation. ${ }^{27}$ Because normal endothelial cells release nitric oxide basally and this nitric oxide may prevent leukocytes from adhering to endothelial cells, decreased basal release of nitric oxide after myocardial ischemia and reperfusion may lead to enhanced adherence of leukocytes to the coronary endothelium, which could enhance leukocyte-induced myocardial injury. ${ }^{28}$

Increased endothelial production of nitric oxide with L-arginine infusion also may be cardioprotective through the action of directly quenching superoxide free radicals. Nitric oxide is a primary radical species and is inactivated by superoxide radicals, ${ }^{11,12}$ but nitric oxide also neutralizes superoxide radicals. ${ }^{13}$ Conditions associated with enhanced production of superoxide have been shown to increase neutrophil adherence. Thus administration of nitric oxide could prevent endothelial injury resulting from superoxide radicals.

In summary, the current experiments strongly suggest a salutary role for endothelial production of nitric oxide in recovery after 2 hours of cold cardioplegic ischemia in neonatal lamb hearts. The beneficial effects of L-arginine after hypothermic ischemia and reperfusion seem likely to involve enhanced endothelial production of nitric oxide and may have clinical application.

We thank Mark A. Cioffi, MAT, for his technical assistance. 


\section{REFERENCES}

1. Kawata H, Sawatari K, Mayer JE Jr. Evidence for the role of neutrophils in reperfusion injury after cold cardioplegic ischemia in neonatal lambs. J THORAC CARDiovasc Surg 1991;103:908-18.

2. Sawatari K, Kadoba K, Berger KA, Daich JA, Mayer $\mathrm{JE} \mathrm{Jr}$. Influence of initial reperfusion pressure after hypothermic cardioplegia on endothelial modulation of coronary tone in neonatal lambs: impaired coronary vasodilation response to acetylcholine. J THORAC Cardiovasc Surg 1991;101:777-82.

3. Palmer RMJ, Ferrige AG, Moncada S. Nitric oxide release accounts for the biological activity of endothelium relaxing factor. Nature 1987;327:524-6.

4. Furchgott RF. Studies on relaxation of rabbit aorta by sodium nitrite: the basis for the proposal that the acid-activatable factor from bovine retractor penis is inorganic nitrite and the endothelium-derived relaxing factor is nitric oxide. In: Vanhoutte PM, ed. Mechanisms of vasodilation. New York: Raven Press, 1986:401-14.

5. Palmer RMJ, Rees DD, Ashton AD, Moncada S. L-Arginine is the physiological precursor for the formation of nitric oxide in endothelium-dependent relaxation. Biochem Biophys Res Comm 1988;153:1251-6.

6. Palmer RMJ, Ashton DS, Moncada S. Vascular endothelial cells synthesize nitric oxide from L-arginine. Nature 1988;333:664-6.

7. Furchgott RF. Role of endothelium in response of vascular smooth muscle. Circ Res 1983;53:557-73.

8. Amezcua JL, Palmer RMJ, De Souza BM, Moncada $\mathrm{S}$. Nitric oxide synthesized from $\mathrm{L}$-arginine regulates vascular tone in the coronary circulation of the rabbit. Br J Pharmacol 1990;97:1119-24.

9. Furlong B, Henderson AH; Lewis MJ, Smith JA. Endothelium-derived relaxing factor inhibits in vitro platelet aggregation. Br J Pharmacol 1987;90:687-92.

10. McCall T, White BJR, Boughton-Smith NK, Moncada S. Inhibition of FMLP-induced aggregation of rabbit neutrophils by nitric oxide. $\mathrm{Br} \mathrm{J}$ Pharmacol 1988;85:517P.

11. Gryglewski RJ, Palmer RMJ, Moncada S. Superoxide anion is involved in the breakdown of endotheliumderived relaxing factor. Nature 1986;320:454-6.

12. Rubanyi GM, Vanhoutte PM. Superoxide anions and hypoxia inactivate endothelium-derived relaxing factor. Am J Physiol 1986;250:H822-7.

13. Rubanyi GM, Ho EH, Cantor EH, Lumma WC, Parker-Botelho LH. Cytoprotective function of nitric oxide: inactivation of superoxide radicals produced by human leukocytes. Biochem Biophys Res Commun 1991;181:1392-7.

14. Takeuchi K, Cao-Danh H, Glynn P, Simplaceanu E, McGown FX, del Nido PJ. Negative inotropic and metabolic effects of the nitric oxide precursors L- arginine: partial preservation by amiloride. Surg Forum 1993;44:264-6.

15. Siegfried MR, Erhardt J, Rider T, Ma XL, Lefer AM. Cardioprotection and attenuation of endothelial dysfunction by organic nitric oxide donors in myocardial ischemia-reperfusion. J Pharmacol Exp Ther 1992; 260:668-75.

16. Johnson G III, Tsao PS, Lefer AM. Cardioprotective effects of authentic nitric oxide in myocardial ischemia with reperfusion. Crit Care Med 1991;19:244-52.

17. Weyrich AS, Ma X-L, Lefer AM. The role of L-arginine in ameliorating reperfusion injury after myocardial ischemia in the cat. Circulation 1992;86:279-88.

18. Nakanishi K, Vinten-Johansen J, Lefer DJ, et al. Intracoronary L-arginine injection during reperfusion improves endothelial function and reduces infarct size. Am J Physiol 1992;263:H1650-8.

19. Fujita H, Yamabe H, Yano T, et al. The effect of intravenously administrated L-arginine on myocardial perfusion abnormality in patients with microvascular angina [Abstract]. J Am Coll Cardiol 1994;23:201A.

20. Fujiwara T, Kurtts TA, Anderson WD, Mayer JE Jr. High-pressure reperfusion injury in neonatal hearts. Surg Forum 1987;38:231-3.

21. Kawata H, Aoki M, Mayer JE Jr. Nitroglycerin improves functional recovery of neonatal lamb hearts after 2 hours of cold ischemia. Circulation 1993; 88(Suppl):II366-71.

22. Macho P, Vatner SF. Effect of nitroglycerin and nitroprusside on large and small coronary vessels in conscious dogs. Circulation 1981;64:1101-7.

23. Nomura F, Aoki M, Mayer JE Jr. Effects of adenosine infusion during reperfusion after cold cardioplegic ischemia in neonatal lambs. Circulation 1993; 88(Suppl):II380-6.

24. Tsao PS, Aoki N, Lefer DJ, Johnson G III, Lefer AM. Time course of endothelial dysfunction and myocardial injury during myocardial ischemia and reperfusion in the cat. Circulation 1990;82:1402-12.

25. Bath PMW, MacGregor GA. Spontaneous nitric oxide donors inhibit monocyte chemotaxis and increase intracellular cGMP concentration. J Vasc Res 1992; 29:170.

26. Kubes P, Suzuki M, Granger N. Nitric oxide: an endogenous modulator of leukocyte adhesion. Proc Natl Acad Sci U S A 1991;88:4651-5.

27. Moilanen E, Vuorinen P, Kankaareranta H, Metsaketela T, Vapaatalo H. NO donors inhibit human neutrophil activation in vivo [Abstract]. J Vasc Res 1992;29:170.

28. Ma XL, Weyrich AS, Lefer DJ, Lefer AM. Diminished basal nitric oxide release after myocardial ischemia and reperfusion promotes neutrophil adherence to coronary endothelium. Circ Res 1993;72: 403-12. 


\section{Discussion}

Dr. Antonio F. Corno (Milan, Italy). We are all aware of the importance of reperfusion damage and, more recently, reoxygenation damage. We demonstrated with experimental research that there is a significant correlation between the importance of myocardial damage and the level of oxygen tension at reperfusion or reoxygenation, especially in the neonatal myocardium; furthermore the level of calcium in the cardioplegic solution is associated with different results. Can you please tell us what oxygen tension you used at reperfusion and what the calcium content of your cardioplegic solution was?

Dr. Stanley K. C. Tam (Boston, Mass.). This study has shown that L-arginine could be an additive to preserve left ventricular function. Do you have any data that will tell us whether L-arginine infusion has any detrimental side effect in the heart and systemically?

Dr. Robert A. Guyton (Atlanta, Ga.). You have used a crystalloid cardioplegic technique in an isolated heart model. Therefore, you have removed from the heart most of the endogenous chemicals. Do you think that this exaggerates the benefit of adding L-arginine? If you used blood cardioplegia or if you used an in vitro heart you might have trace levels of L-arginine.

Dr. Frederick L. Grover (Denver, Colo.). Is it possible that what we are seeing here is preconditioning, or some form of that?

Dr. Hiramatsu. Dr. Corno asked about the oxygen tension during reperfusion and the calcium content of the cardioplegic solution. The gas supplied to the oxygenator was $95 \%$ oxygen $/ 5 \%$ carbon dioxide during the first 20 minutes of reperfusion, to mimic the circumstances under which reperfusion on cardiopulmonary bypass occurs clinically. When the hemodynamic measurements were made at 30 minutes of reperfusion, the gas supplied to the oxygenator was $20 \%$ oxygen, $75 \%$ nitrogen, and $5 \%$ carbon dioxide. There was no calcium in the cardioplegic solution.

Dr. Tam asked about detrimental systemic effects. We have carried out acute experiments in the whole animal, as well as in the isolated heart, and have found no detrimental side effects.

Dr. Guyton asked if the results would be the same if blood cardioplegia were used or if an in vivo model were used. We have not done experiments with blood cardioplegia, but in whole animal experiments carried out by Dr. Joseph Forbess in our laboratory, L-arginine infusions during reperfusion improved the recovery of preload recruitable stroke work after 2 hours of deep hypothermic circulatory arrest.

Dr. Grover asked if our observations with L-arginine are related to preconditioning. As far as we know, preconditioning is thought to be related either to adenosine or to potassium channels, and we do not believe that $\mathrm{L}$-arginine has any effects on either adenosine or potassium channels. 